\title{
SOBRE EL DEBER DE TOLERAR LA ACCIÓN DE SALVAGUARDA EN LOS CASOS DE ESTADO DE NECESIDAD AGRESIVO
}

\author{
Daniel González Lagier*
}

\section{Introducción}

En su artículo Derechos de necesidad agresiva y deberes de tolerancia, Silva Sánchez, de manera profunda y sugerente, plantea a propósito del estado de necesidad una cuestión que puede servir de banco de pruebas para algunos conceptos y herramientas desarrollados desde la teoría del Derecho. Esta cuestión es la siguiente: es pacífico aceptar que quien actúa en estado de necesidad no realiza una acción antijurídica. Esto implica que el Estado tiene un deber de tolerar este tipo de conductas (a las que, siguiendo a la doctrina penal, llamaré "acciones de salvaguarda"). Ahora bien, ¿qué ocurre con el sujeto afectado por la acción de salvaguarda, esto es, el tercero que ve que alguno o algunos de sus derechos son lesionados para que pueda superarse tal estado? ¿Tiene también el deber de tolerar tal acción? Si trata de impedir la lesión de su derecho, ¿incurre en algún tipo de responsabilidad?

Existen, según Silva Sánchez, dos posibles respuestas obvias a este interrogante: 1) Si el tercero interfiere impidiendo la acción de salvaguarda no ocurre nada, puesto que no tiene el deber de tolerarla. 2) Si el tercero

* Universidad de Alicante, España. 


\section{Daniel González Lagier}

impide la acción de salvaguarda, incurre él mismo en alguna conducta antijurídica, puesto que tiene el deber de tolerarla ${ }^{1}$.

La primera respuesta le parece paradójica a este autor, puesto que la situación jurídica sería tal que el sujeto que actúa en estado de necesidad, si tiene éxito, no realiza un acto antijurídico, pero no es respaldado por el Derecho si alguien interfiere su conducta. Silva Sánchez opta por la segunda respuesta, esto es, por la existencia de un deber de tolerar por parte del tercero, respaldado por el Derecho -y su artículo está dirigido a dotar de contenido este deber de tolerancia y a justificarlo-.

En lo que sigue, siguiendo a Borja Martínez, entenderé que hay estado de necesidad cuando se dan las siguientes circunstancias:

“a) Existencia de un mal grave e inminente, propio o ajeno, que se proyecta en la puesta en peligro de un bien jurídico o en el inicio de su menoscabo, de tal forma que sólo a través de una acción contundente pueda conjurarse el peligro.

b) Necesidad de evitar el menoscabo del bien jurídico a través de la lesión de otro bien jurídico o de la infracción de un deber. Es decir, la perpetración de otro mal, la merma de un interés, la comisión de un delito, se constituye en el único medio para llevar a cabo la acción de tutela.

c) Que el mal perpetrado no sea mayor que aquél que se quiere evitar. Dicho de otra forma: debe existir una ponderación de bienes jurídicos, de tal forma que el tutelado debe ser de igual o mayor entidad que este otro que se menoscaba. Esta evaluación debe llevarse a cabo desde un doble plano. Desde el prisma abstracto, debe contemplarse el valor de cada bien jurídico en sí mismo considerado (por ejemplo, la vida humana es valor superior que la

\footnotetext{
${ }^{1}$ Usaré la expresión "deber de tolerancia”, que parece ser la que usa la doctrina penal para estos casos, pero quizá sería más apropiado hablar de "deber de sacrificio", puesto que parece haber algo de contradictorio en la idea de que pueda existir un deber de tolerar: para poder tolerar algo hace falta tener la facultad de prohibirlo.
} 
— Sobre el deber de tolerar la acción de salvaguarda en los casos de estado de necesidad agresivo propiedad). Desde el prisma concreto, por el contrario, se toma en consideración los intereses y perjuicios atendiendo a las específicas condiciones que pueda deparar la situación objeto de examen (así, un hurto perpetrado para solventar problemas económicos puede estar exento, o no, de responsabilidad criminal según las condiciones reales en las que se encuentra el infractor y su familia).

d) Que dicha situación de necesidad no haya sido provocada intencionalmente por el sujeto.

e) Que el sujeto no esté obligado, merced al oficio que desempeña o al cargo que ocupa, a sufrir los males derivados de esas situaciones profesionales, las cuales imponen un deber especial de sacrificio"2

Por lo demás, ciñéndome al objeto del artículo de Silva Sánchez, me referiré exclusivamente al estado de necesidad agresivo, esto es, a aquel en el que -a diferencia de lo que ocurre en el estado de necesidad defensivo- el peligro para el sujeto que se encuentra en situación de necesidad no es imputable al sujeto cuyos bienes jurídicos pueden verse afectados por la acción de salvaguarda ${ }^{3}$.

\section{Las modalidades jurídicas de Hohfeld}

La cuestión expuesta en el anterior epígrafe puede plantearse usando las modalidades jurídicas de Hohfeld ${ }^{4}$. Como es sabido, este autor trató

\footnotetext{
${ }^{2}$ Emiliano Borja Martínez, Las circunstancias atenuantes en el ordenamiento jurídico español, Ed. Tirant lo Blanch, Valencia, 1999, pág. 105.

${ }^{3}$ Francisco Baldó Revilla, Estado de necesidad y legítima defensa, J.M. Bosch Editor, Barcelona, 1994, pág. 22.

${ }^{4}$ Expuestas por este autor en W.N. Hohfeld, Conceptos jurídicos fundamentales, Ed. Fontamara, México, 1991.
} 
de analizar la noción de derecho subjetivo proponiendo una reconstrucción precisa de los distintos significados de este concepto a partir de los variados $\mathrm{y}$, a veces, entrelazados usos que los juristas hacen del mismo ${ }^{5}$. Hohfeld distingue cuatro modalidades jurídicas activas (la libertad o privilegio, el derecho en sentido estricto, la potestad y la inmunidad) y cuatro modalidades jurídicas pasivas (el no-derecho, el deber, la sujeción y la incompetencia). Cada una de ellas puede definirse por su modalidad correlativa y su modalidad opuesta.

Así, si $A$ tiene frente a $B$ la libertad de hacer $x, B$ no tiene frente a $A$ el derecho (está en una situación de no-derecho) de exigir que $A$ se abstenga de realizar $x$. Si $A$ tiene frente a $B$ el derecho de que éste haga $x, B$ tiene frente a $A$ el deber de hacer $x$. Si $A$ tiene la potestad de producir ciertos efectos jurídicos respecto de $B$ mediante el acto $x, B$ está en una posición de sujeción frente a $A$ (su posición jurídica se verá modificada por los efectos del acto $x$ ). Por último, si $A$ está en una situación de inmunidad frente a $B$ respecto de los efectos jurídicos de la acción $x, B$ es incompetente para alterar el estatus jurídico de $A$ mediante el acto $x$.

En definitiva, estas relaciones de correlación pueden representarse mediante el siguiente esquema:

Correlativos

Libertad - no-derecho
Derecho en
sentido estricto
potestad
inmunidad

Por otra parte, si $A$ tiene frente a $B$ la libertad de hacer $x$, entonces queda excluido que tenga el deber de hacer $x$ frente a $B$ (la libertad de

\footnotetext{
${ }^{5}$ Véase la nota preliminar de Genaro Carrió a W.N. Hohfeld, Conceptos jurídicos fundamentales, págs. 10 y ss. En lo que sigue resumo el trabajo de Hohfeld y la presentación de Carrió.
} 
- Sobre el deber de tolerar la acción de salvaguarda en los casos de estado de necesidad agresivo

hacer $x$ y el deber de hacer $x$ son opuestos o excluyentes). Si $A$ tiene frente a $B$ el derecho de hacer $x$, queda excluido que esté frente a $B$ en una situación de no-derecho de hacer $x$. Si $A$ tiene frente a $B$ la potestad de afectar su situación jurídica mediante el acto $x$, entonces queda excluido que sea incompetente para afectar la posición jurídica de $B$ mediante el acto $x$. Por último, si $A$ es inmune frente a $B$ para que éste modifique su posición jurídica mediante el acto $x$, queda excluido que $A$ esté en una situación de sujeción frente a $B$ respecto del acto $x$.

En definitiva, estas relaciones de oposición son las siguientes:

Opuestos

Libertad / deber

Derecho / no-derecho

potestad / incompetencia

inmunidad/sujeción

A veces los juristas hablamos, de una manera imprecisa, de derecho subjetivo para referirnos a lo que Hohfeld llama libertad o privilegio; otras, para referirnos a lo que llama derecho en sentido estricto; otras para referimos a una potestad, y otras para referirnos a una situación de inmunidad. De esta manera, las nociones de Hohfeld pueden servirnos para precisar en qué sentido un sujeto tiene un determinado derecho subjetivo (si se quiere, para distinguir algunos tipos de derechos subjetivos).

En ocasiones, las modalidades jurídicas pueden darse conjuntamente. Así, como señala Carrió:

"Decir que A es propietario del objeto Z, importa afirmar que A tiene, frente a cada uno de los otros miembros de la comunidad, un cúmulo de derechos, privilegios, potestades e inmunidades superpuestos, relativos al objeto Z. A tiene el derecho de que B (otro miembro de la comunidad) no use el objeto Z; tiene, frente a B, el privilegio de usarlo; tiene, frente a $\mathrm{B}$, la potestad de abandonarlo; tiene, frente a B, la inmunidad consistente en que este último no puede, 
digamos, enajenar dicho objeto. A puede, sin embargo, en sus relaciones con $\mathrm{B}$ (o con cualquier otro miembro de la comunidad), limitar ese cúmulo de derechos, privilegios, potestades e inmunidades. Por ejemplo, concediendo a B el derecho (o el mero privilegio) de usar el objeto, o comprometiéndose frente a $\mathrm{B}$ a no usarlo, $\mathrm{u}$ otorgando a éste la potestad de venderlo".

Conviene, por tanto, distinguir tres sentidos de la expresión "derecho" (subjetivo): (1) "derecho en sentido estricto", que se refiere al correlativo de un deber; (2) "derecho en sentido indeterminado", que se refiere a alguna de las modalidades jurídicas activas; y (3) "derecho en sentido amplio", que se refiere a un conjunto de derechos en sentido estricto y/o libertades y/o potestades y/o inmunidades (por ejemplo, cuando hablamos del derecho de propiedad) ${ }^{7}$.

\section{El derecho de quien actúa en estado de necesidad como una libertad o privilegio}

¿Cuál es, en términos de las modalidades jurídicas de Hohfeld, la posición jurídica del sujeto que actúa en estado de necesidad (lo que, correlativamente, nos dará la posición del sujeto pasivo de la acción de salvaguarda)? Dado que nos planteamos la relación entre el sujeto que actúa en estado de necesidad y el sujeto afectado por la acción de salvaguarda, las modalidades candidatas son la libertad y el derecho en sentido estricto (mientras que si analizáramos la situación del sujeto

\footnotetext{
${ }^{6}$ Genaro Carrió, en W. N. Hohfeld, Conceptos jurídicos fundamentales, pág. 15.

${ }^{7}$ Tomo esta distinción de Juan Antonio Cruz Parcero, El concepto de Derecho subjetivo, Ed. Fontamara, colección Doctrina jurídica contemporánea, México, 1999, pág. 298. Para una presentación detallada de las modalidades jurídicas de Hohfeld véase el capítulo II.
} 
— Sobre el deber de tolerar la acción de salvaguarda en los casos de estado de necesidad agresivo necesitado y el tercero afectado por la acción de salvaguarda frente al Estado, las modalidades adecuadas serían las de inmunidad y sujeción: la posición frente al Estado de quien actúa en estado de necesidad podría verse como una inmunidad respecto de la potestad de éste de imponerle una pena por la lesión del derecho correspondiente, y la posición del sujeto afectado por la acción de salvaguarda podría verse, en determinados casos, como una sujeción frente a la potestad sancionadora del Estado).

Supongamos que afirmamos que quien actúa en estado de necesidad tiene libertad frente a otro sujeto para realizar la acción de salvaguarda. La acción de salvaguarda consiste en una acción que, directa o indirectamente (como consecuencia de la misma), lesiona algún derecho de otro sujeto. Decir que el sujeto que actúa en estado de necesidad tiene la libertad o el privilegio de lesionar alguno de los derechos del otro sujeto implica, de acuerdo con la definición de Hohfeld, que, jurídicamente, puede hacerlo (esa conducta no le está prohibida y, por tanto, no es antijurídica, aunque en otra situación sí lo sería) y que el sujeto afectado no tiene el derecho de exigir que se abstenga (por tanto, el sujeto necesitado no tiene el deber de abstenerse). Ahora bien, de aquí no se infiere que el sujeto afectado por la acción de salvaguarda tenga el deber de tolerar dicha acción, esto es, no se infiere que no pueda tratar de evitar o impedir la lesión.

La situación sería semejante a lo que ocurre en un combate de boxeo, por usar el conocido ejemplo de Genaro Carrió ${ }^{8}$. Las reglas del boxeo prohíben cierto tipo de golpes, como los golpes bajos y los cabezazos. Sin embargo, ¿qué ocurre con la posibilidad de propinar un golpe correcto? Es obvio que las reglas del boxeo no le prohíben a un púgil propinar con el puño un golpe en la mandíbula del adversario. Ahora bien, el otro púgil no tiene el deber de tolerar ese golpe sino que puede tratar de impedirlo. Por ello, la relación queda mejor descrita diciendo que

${ }^{8}$ En la introducción a W.N. Hohfeld, Conceptos jurídicos fundamentales. 
el púgil $A$ tiene la libertad de golpear correctamente al púgil $B$ (y viceversa) que adscribiéndole a uno u otro un derecho en sentido estricto que implique el deber del contrario de tolerar el golpe.

Optar por esta posibilidad, esto es, por interpretar que quien actúa en estado de necesidad tiene la libertad o el privilegio de afectar los derechos de otro sujeto para superar el estado de necesidad, no tiene por qué verse como una situación paradójica, a pesar de lo que afirma Silva Sánchez. Las libertades, definidas de esta manera, son una modalidad frecuente. Están asociadas a todos aquellos casos en los que el Derecho no se refiere a una determinada acción ni para prohibirla ni para permitirla expresamente (lo que Alchourrón y Bulygin llaman permiso débil $l^{9}$ ) y a muchas acciones permitidas en sentido fuerte (esto es, expresamente permitidas por el ordenamiento jurídico), si no existe una prohibición de tratar de impedir la conducta (se puede discutir si en el primer caso son libertades jurídicas, pero no lo haré aquí).

Por otro lado, tener solamente una libertad o un privilegio, aunque implica un grado menor de protección jurídica que tener un derecho en sentido estricto, no conlleva que se carezca totalmente de protección jurídica para realizar la acción correspondiente. Volviendo al ejemplo del boxeo: aunque el púgil $A$ tenga sólo la libertad (y no el derecho en sentido estricto) de propinar un golpe con el puño en la mandíbula del contrincante, el púgil $B$ no puede tratar de impedirlo de cualquier manera, sino que ha de respetar las reglas del boxeo, que trazan un perímetro de obligaciones y prohibiciones que, indirectamente, protegen la libertad (aunque no frente a todo tipo de acciones).

De igual manera, en el caso del estado de necesidad, afirmar que el sujeto necesitado tiene una libertad no implica que su acción no esté protegida jurídicamente: en primer lugar, ve cancelada una prohibición (la de lesionar los derechos del afectado) que, en otras circunstancias, tendría y, por

\footnotetext{
${ }^{9}$ Carlos Alchourrón y Eugenio Bulygin, Introducción a la metodología de las ciencias jurídicas y sociales, Ed. Astrea, Buenos Aires, 1987, pág. 176.
} 
tanto, el sujeto afectado no puede exigir jurídicamente que el sujeto necesitado se abstenga; en segundo lugar, el primero no puede impedir de cualquier manera la acción de salvaguarda (algo obvio: la acción con la que se opone a la acción de salvaguarda no puede violar una norma jurídica). En palabras de Hart:

"... donde un hombre es dejado en libertad por el Derecho para realizar o no alguna acción particular, esa acción de algún modo estará protegida por el Derecho, aun si no existe una obligación correlativa de no interferir por parte de otros. Esto es así porque en última instancia las formas más toscas (o agresivas) de interferir, como aquellas que comprenden el daño físico o violación de la propiedad, serán consideradas como delitos o como ilícitos civiles, o incluso ambas cosas. De esta forma, los deberes y obligaciones de no realizar interferencias de ese tipo constituyen un perímetro protector detrás del cual existen las libertades y pueden ejercitarse" 10 .

En definitiva:

a) La tesis de la correlatividad entre derechos y deberes debe ser matizada: se pueden tener cierto tipo de derechos (una libertad, una potestad o una inmunidad) de realizar $x$ sin que exista un deber correlativo.

b) Tener meramente una libertad o privilegio no implica necesariamente carecer de protección jurídica.

c) Tener una libertad no es una situación extraña o paradójica.

En la definición de estado de necesidad de la que hemos partido se contempla el caso en el que los bienes jurídicos en juego (el que se quiere

${ }^{10}$ H.L.A. Hart, "Legal Rights", en Essays on Bentham. Jurisprudence and Political Theory, Clarendon Press, Oxford, 1982, págs. 162 y ss. 
proteger y el que es puesto en peligro) sean igualmente relevantes. Pues bien, en estos casos es plausible sostener que no sería razonable que el Derecho optara por la protección de uno de ellos en detrimento del otro (no tiene razones para hacerlo), salvo en los supuestos en los que el peligro para el sujeto necesitado haya sido causado por el tercero que sufre las consecuencias de la acción de salvaguarda (los casos de estado de necesidad defensivo). Por tanto, se puede pensar que ambos sujetos tienen una libertad o privilegio frente al otro: el sujeto necesitado tiene la libertad de realizar la acción de salvaguarda poniendo en peligro o lesionando los bienes del tercero y éste tiene la libertad de tratar de impedírselo. ${ }^{11}$ En lo que sigue no me volveré a ocupar de estos supuestos.

\section{El derecho de quien actúa en estado de necesidad como un derecho en sentido estricto}

¿Qué ocurre con el resto de casos (probablemente la mayoría), en los que el bien jurídico que el sujeto necesitado (o su auxiliador) trata de proteger es mayor que el bien jurídico del tercero que puede verse lesionado? Supongamos que, en estos casos, quien realiza la acción de salvaguarda tiene un genuino derecho (derecho en sentido estricto) de realizarla frente al sujeto afectado por ella. Esto implicaría que el sujeto afectado tiene el deber de tolerar la injerencia del otro sujeto en su esfera de derechos y que si incumple este deber él mismo realizaría una acción antijurídica.

${ }^{11}$ Probablemente sería posible hacer nuevos matices en función de que la acción de salvaguarda ponga meramente en peligro los bienes del tercero o los lesione con seguridad, o en función de que el tercero impida totalmente la acción de salvaguarda o sólo la dificulte. También puede resultar difícil la comparación y ponderación entre los bienes jurídicos en juego para determinar si merecen la misma o distinta protección y en qué circunstancias. Sin embargo, ciñéndome al trabajo de Silva Sánchez, no me detendré en estas dificultades. 
- Sobre el deber de tolerar la acción de salvaguarda en los casos de estado de necesidad agresivo

El contenido del deber del sujeto afectado por la acción de salvaguarda, si ha de ser un deber autónomo, no debería consistir meramente en respetar el perímetro normativo que rodea al derecho del sujeto necesitado (esto es, no debería consistir meramente en no impedirle su objetivo usando la violencia física o por cualquier otro medio ilícito, porque entonces no es un genuino deber de tolerar la acción de salvaguarda, ni debería ser un deber derivado de alguna otra situación distinta al estado de necesidad), sino que ha de tratarse de un deber genérico de no impedir la acción de salvaguarda de ninguna manera. Cualquier acción (u omisión) que se pueda interpretar como "impedir la acción de salvaguarda" queda prohibida. Por ello, la protección que el Derecho daría en este caso al sujeto necesitado sería una protección directa y completa.

La interferencia que impide la acción de salvaguarda puede consistir en una acción (por ejemplo, esconder dinero) o en una omisión (por ejemplo, no abrir una puerta). De manera que el deber de tolerancia se materializa, según el contexto, unas veces en un deber de actuar y otras veces en un deber de omitir. Esto mismo afirma Silva Sánchez, cuando distingue los dos siguientes supuestos:

"Cabe, así, en primer lugar, que la infracción del deber de tolerancia se manifieste sencillamente en la resistencia pasiva a (o en la falta de colaboración activa con) la conducta del sujeto necesitado o de su auxiliador. En estas situaciones, que a mi entender constituye el grupo de infracciones menos graves del deber de tolerancia, sí nos hallamos ante casos de mera infracción del deber de solidaridad mínima interpersonal, que merecen el mismo tratamiento que las omisiones de socorro.

Ahora bien, cabe, en segundo lugar, que el afectado por la conducta del necesitado o de su auxiliador no se limite a la resistencia pasiva, sino que, ciertamente manteniéndose en su esfera jurídica originaria, neutralice la conducta del necesitado o de su auxiliador, ya mediante una oposición directa activa, ya mediante la sustracción de los bienes que éstos pretendían alcanzar. Esta situación, a la que esencialmente se dedican estas páginas, es distinta y más grave que la anterior. Como veremos, en ella cabe fundamentar una responsabilidad por la lesión sufrida por los bienes jurídicos del necesitado, así como por la coacción ejercida sobre el auxiliador en el caso de que éste sea alguien distinto del propio necesitado". 
Ahora bien, como se puede apreciar, Silva Sánchez justifica un alcance distinto de la infracción del deber de tolerancia según que éste se realice por medio de una acción o por medio de una omisión. Si el sujeto afectado impide la acción de salvaguarda por medio de una omisión, entiende que se trata de un caso de omisión del deber de socorro (o análogo a estos casos). Si la impide por medio de una acción (aunque manteniéndose en su "esfera jurídica originaria"), entonces sugiere que se puede imputar al sujeto afectado un delito correspondiente a la lesión del bien jurídico que tenga lugar (homicidio, lesiones, coacciones, etc.). Ahora bien, estas consideraciones permiten plantear dos cuestiones:

a) La primera cuestión es si la mera diferencia entre actuar y omitir puede fundamentar en este caso esa diferencia de responsabilidad. ¿Por qué es más grave actuar que omitir? ¿Por qué es más grave cerrar la puerta a quien necesita entrar en nuestra vivienda para evitar un mal que no abrírsela?

b) La segunda cuestión es si esta responsabilidad más grave se deriva directamente de la infracción del deber de tolerancia que tiene el sujeto $B$ como consecuencia del estado de necesidad en el que se halla el sujeto $A$, o bien se deriva simplemente de un deber más general, en cuyo caso no estaría vinculado a la infracción del deber de tolerancia, sino a la infracción de deberes que tendría en todo caso (al margen del hecho de ser el sujeto afectado por la acción de salvaguarda) y que forman parte del perímetro normativo que rodea al estado de necesidad.

\section{Actuar y omitir}

¿Cómo puede justificarse la diferencia de tratamiento entre quien impide la "acción de salvaguarda" por medio de una acción y quien la impide por medio de una omisión?

El concepto de acción (en un sentido amplio, que engloba a las omisiones) es sumamente complejo. Parte de esta complejidad (y de las 
discusiones acerca de este concepto tanto en la filosofía de la acción como en la dogmática penal) tiene que ver con que las acciones son, por decirlo así, "habitantes de dos mundos distintos": por un lado, las acciones son movimientos corporales (o ausencia de los mismos) relacionados causalmente con cambios y, por tanto, pertenecen al mundo físico, causal o natural; por otro lado, son objeto de descripciones o interpretaciones (a veces desde un punto de vista subjetivo o intencional, otras desde un punto de vista social), las dotamos de cierto significado y, por tanto, pertenecen también al mundo de los significados. Todo movimiento corporal (o ausencia del mismo) voluntario es objeto de interpretaciones o descripciones a la luz de las circunstancias en las que tiene lugar, la intención del agente, las consecuencias que produce y sus repercusiones sociales. Estas interpretaciones pueden encadenarse unas a otras (es lo que Alvin Goldman llama "generación de acciones"12), comenzando con la descripción de un movimiento corporal, o la ausencia de un movimiento corporal, y haciéndose cada vez más complejas. Así, un mismo "tramo de conducta" puede describirse como flexionar el dedo sobre un gatillo, disparar, asesinar al archiduque Francisco Fernando de Austria, irritar a las potencias hegemónicas de la época o hacer saltar la chispa que provocó la primera Guerra Mundial (existe en la filosofía analítica de la acción un debate acerca de si lo que llamamos "acción" se corresponde con el tramo de comportamiento que da lugar a todas esas interpretaciones, esto es, con la secuencia de movimientos corporales, o con alguna, algunas o, incluso, todas las interpretaciones, pero no es una cuestión esencial para nuestra discusión y, en mi opinión, acaba reduciéndose a una mera disputa terminológica). Por ello, conviene distinguir entre (1) el tramo de comportamiento previo a la interpretación (el tramo de comportamiento que es objeto de la interpretación o descripción) y (2) el comportamiento

${ }^{12}$ Alvin Goldman, A Theory of Human Action, Princeton University Press, 1971. 
interpretado. Me referiré a (1) como conducta o comportamiento y a (2) como acción u omisión ${ }^{13}$.

Cuando calificamos un comportamiento como una omisión, estamos asumiendo una determinada interpretación del mismo a la luz de lo que el agente dejó de hacer. Lo que es relevante para interpretar un comportamiento como una omisión no es una actitud pasiva en términos globales, sino la ausencia del comportamiento que hubiera dado lugar a un cambio en el mundo para el cual el agente tenía una razón (en el caso del Derecho, un deber jurídico). Por tanto, no estamos haciendo referencia a si el agente se mantuvo o no en total pasividad; estamos poniendo el acento en que no se ha realizado una acción determinada ${ }^{14}$. Dado que la calificación como omisión de un comportamiento es relativa a una acción o un cambio determinado, un mismo comportamiento puede ser calificado de omisión, respecto de un cambio que no tuvo lugar, y al mismo tiempo de acción, respecto de un cambio que ha tenido lugar. El mismo tramo de comportamiento puede describirse como cocinar $\mathrm{u}$ omitir cerrar el grifo de la bañera. Incluso algunas omisiones, por ejemplo, omitir guardar silencio, únicamente pueden producirse por medio de una actividad positiva (hablar o hacer ruido).

Lo mismo ocurre con la omisión del deber de socorro: el comportamiento que se califica de esa manera puede ser un comportamiento activo o pasivo. Si no abrir una puerta, impidiendo que el sujeto necesitado se salve, es una omisión del deber de socorro, no es porque sea un comportamiento pasivo en sí mismo, sino porque puede

\footnotetext{
${ }^{13}$ Aunque otros autores prefieren llamar a (1) acción y a (2) descripción de una acción. Por ejemplo, Davidson, Anscombe, etc. Sobre esta discusión y los problemas de individualización de acciones puede verse Daniel González Lagier, The Paradox of Actions (Human Actions, Law and Philosophy), Ed. Kluwer Academia Publishers, 2003 (Hay versión en castellano: Las Paradojas de la acción, Publicaciones Universidad de Alicante, 2000).

${ }^{14}$ En esencia, ésta es también la noción de omisión de Silva Sánchez. Véase, El delito de omisión. Concepto y sistema, Ed. B de F, Montevideo-Buenos Aires, 2003.
} 
ser interpretado o descrito como no auxiliar al sujeto en peligro. De la misma manera, cerrarle la puerta puede ser descrito también, en las circunstancias apropiadas, como no prestarle auxilio, por lo que también puede ser una omisión del deber de socorro.

Si el resultado o la consecuencia del comportamiento es el mismo (el incumplimiento del deber de auxiliar), entonces no se ve por qué la diferencia en el nivel del comportamiento (esto es, la conducta, activa o pasiva, que se califica de omisión del deber de socorro) ha de marcar una diferencia en cuanto a la responsabilidad del agente, siendo la misma la interpretación de tal comportamiento. Esto es algo que en el Derecho penal se acepta implícitamente cuando se acepta la modalidad de comisión por omisión; sin embargo, la intuición de que es más grave actuar que omitir parece bastante arraigada.

A veces se ha dicho que las acciones suelen venir acompañadas de una intención o dolo especial, que no acompaña a las omisiones (requiere mayor intención actuar que omitir, diría este argumento). Pero esto, obviamente, es una generalización abierta a muchas excepciones (quien se deleita viendo morir a otro en medio de fuertes sufrimientos sin ayudarle, pudiendo hacerlo sin esfuerzo, exhibe un dolo mayor que quien mata a otro en un ataque de ira) y lo único que muestra es que lo relevante a efectos de establecer la responsabilidad es la intención o falta de la misma, y no que la conducta sea activa o pasiva.

Otras veces se ha buscado el fundamento de la afirmación de que es más grave actuar que omitir en el hecho de que mientras que las acciones (los comportamientos activos) son causa de resultados, las omisiones, al ser fenómenos negativos, no pueden iniciar cadenas causales. Por tanto, por medio de acciones producimos cambios en el mundo mientras que, por medio de omisiones, permitimos que se produzcan, pero no los producimos.

Sin embargo, esta idea parece provenir de una concepción de la causalidad que no se corresponde con el uso común que realizamos de este concepto, donde no es extraño imputar efectos causales a fenómenos negativos ("La falta de lluvia es la causa de la pérdida de las cosechas", decimos). Aquello que causa un determinado efecto es siempre un conjunto 
de condiciones, y no sólo un elemento aislado. Así, si se distingue entre contexto causal (el conjunto de condiciones que produce un estado de cosas) y causa (la condición que aparece como relevante porque es extraña en ese contexto), entonces parece que la imputación de efectos causales a fenómenos negativos (incluyendo omisiones) puede explicarse satisfactoriamente. Para que se produzca un incendio hace falta que se dé un conjunto de condiciones (presencia de oxígeno en el aire, escasa humedad, un cigarro mal apagado, etc.). Todas estas condiciones constituyen el contexto causal, pero sólo consideramos causa del incendio a una de ellas: aquella cuya presencia en el contexto sea anormal; en nuestro ejemplo, el cigarro mal apagado (obsérvese lo absurdo que sería decir en este caso que la causa del incendio es la presencia de oxígeno). La condición que consideramos anormal en el contexto puede ser también una omisión: si se estropea el motor de mi coche porque viajo a un lugar muy frío sin poner líquido anticongelante en el sistema de refrigeración, la causa de la avería será mi omisión (porque será lo anormal en el contexto, de acuerdo con elementales reglas de precaución), no el hecho de que la temperatura bajara por debajo de $0^{\circ} \mathrm{C}$. un día de frío invierno (que será sólo una condición dentro del contexto causal). En el caso de las omisiones relevantes jurídicamente, lo que señala como anormal a una de las condiciones es que ésta implica la vulneración de un deber ${ }^{15}$.

\footnotetext{
${ }^{15}$ Quizá sería más apropiado decir "la vulneración de un deber suficientemente relevante". En efecto, la doctrina penal acepta que algunos casos de omisiones -por ejemplo, si se tiene un deber de garante- dan lugar (causan) un resultado (en comisión por omisión), mientras que otras omisiones (las que se califican como meras omisiones del deber de socorro) no. Creo que la respuesta debe consistir en sostener que la omisión de un deber de socorro no es lo suficientemente anormal (el deber no es lo suficientemente fuerte) como para individualizar tal omisión como causa del resultado lesivo. En El delito de omisión, Silva Sánchez opta por negar el papel causal de las omisiones en todo caso (págs. 293 y ss.), pero me parece que eso hace difícil justificar la imputación de responsabilidad por la lesión producida en los casos de comisión por omisión y obliga a buscar alternativas ad hoc para la causalidad (por ejemplo, Silva Sánchez se ve obligado a sostener que "la posición de garante (...) actúa como equivalente funcional de la causalidad”, pág. 294).
} 
— Sobre el deber de tolerar la acción de salvaguarda en los casos de estado de necesidad agresivo

Esta concepción de la causalidad pone de manifiesto su carácter a la vez natural y normativo (o relativo a regularidades): la relación entre todo el contexto causal y el efecto es una relación natural, en el mundo físico, mientras que la selección de una de las condiciones que integran el contexto como causa del efecto es una cuestión normativa, lo cual es evidente en el caso de las omisiones (como dicen Hart y Honoré, si las flores de un jardín se mueren diremos que la causa fue la omisión del jardinero encargado de cuidarlas, y no la de los vecinos).

En otras ocasiones se ha tratado de fundamentar la diferencia en la valoración de la gravedad de las acciones y las omisiones en el hecho de que una omisión siempre deja abierta la posibilidad de que otro sujeto impida el resultado. No evitar la muerte de alguien que se está ahogando es menos grave que sujetarlo bajo el agua para ahogarlo porque el primer curso de acción deja abierta la posibilidad de que otro sujeto ayude a la víctima. Dicho de otra manera: para que se produzca un determinado cambio en el mundo como consecuencia de una omisión, es necesario que también el resto de agentes deje de producir ese cambio, pero esto -se dice- no ocurre con las acciones, en las que la mera realización de la acción es suficiente para producir la consecuencia ${ }^{16}$. En términos causales, se podría decir que mientras una acción es una condición suficiente para cerrar el contexto causal, una omisión sólo pone una condición necesaria (pero no suficiente) de cierre del contexto causal (que ha de completarse con las omisiones del resto de agentes).

Este argumento, sin embargo, olvida que en muchas ocasiones entre la realización de cierto movimiento corporal y su consecuencia puede transcurrir un determinado lapso de tiempo que puede hacer que un tercero

\footnotetext{
${ }^{16}$ Esto hacía dudar a von Wright acerca de si las omisiones tienen resultado, a diferencia de las acciones. Sobre esta cuestión y la distinción entre resultado y consecuencia en von Wright, véase G.H. von Wright, Action Theory as a Basis for Deontic Logic, Libera Universita degli Studi di Trento, 1981. En general, sobre el concepto de acción de von Wright, puede verse Daniel González Lagier, Acción y norma en G.H. von Wright, Centro de Estudios Constitucionales, Madrid, 1995.
} 
impida que se produzca la consecuencia: por ejemplo, si disparo un arma apuntando a un peatón y alguien se interpone entre el disparo y la víctima, la consecuencia deseada por mí no se producirá. De manera que para que un cambio en el mundo tenga lugar como consecuencia de mi acción también puede ser necesario que otros sujetos omitan impedir que se produzca ese cambio, luego las acciones también pueden estar abiertas a que otros sujetos impidan que se produzca el cambio pretendido. De manera que, aquí, tampoco se da una diferencia relevante entre acciones y omisiones.

\section{Las consecuencias jurídicas de la infracción del deber de tolerancia}

Si las anteriores consideraciones son acertadas, las consecuencias de la violación del deber de tolerancia no varían por el hecho de que la acción de salvaguarda se haya impedido por medio de una acción o de una omisión. De manera que una posibilidad es considerar que cualquier infracción del deber de tolerancia debe calificarse como una infracción del deber de socorro: quien, consciente de que algún bien jurídico de otro sujeto está en peligro y de que su salvación requiere la lesión de algún derecho suyo de menor relevancia, impide la acción de salvaguarda, está dejando de socorrer al otro sujeto, tanto haya impedido la acción de salvaguarda por medio de una acción como lo haya hecho por medio de una omisión.

Sin embargo, puede ocurrir que el sujeto que se ve afectado por la acción de salvaguarda esté en una posición de garante respecto del sujeto necesitado. En este caso, su omisión es más grave y, probablemente, de acuerdo con la doctrina y la jurisprudencia se le puede hacer responsable de las lesiones producidas en los bienes jurídicos del sujeto necesitado en comisión por omisión ${ }^{17}$.

\footnotetext{
${ }^{17}$ Aunque se puede tener la sensación de que el "salto" entre la omisión del deber de socorro y la comisión por omisión puede ser excesivo y de que sería conveniente alguna figura intermedia.
} 


\section{— Sobre el deber de tolerar la acción de salvaguarda en los casos de estado de necesidad agresivo}

Una cuestión que puede plantearse es si, en realidad, la posición de garante no concurre siempre en el sujeto que impide, por acción u omisión, la acción de salvaguarda. Creo que habría dos vías para sostener esto:

(1) En primer lugar, se podría decir que el hecho de que la acción de salvaguarda requiera necesariamente (o bien porque no hay otra alternativa, o bien porque ésta es la más eficiente) la lesión del bien jurídico del tercero, coloca a éste en posición de garante, puesto que no hay otra manera (o no hay otra manera igualmente eficaz) de evitar el perjuicio para el sujeto necesitado. Pero, en mi opinión, esta vía ampliaría demasiado el concepto de garante, ya que este estatus no dependería de ninguna acción o del consentimiento del sujeto que se consideraría como tal (sin embargo, si existe una gran desproporción entre el bien jurídico del sujeto en estado de necesidad y el bien jurídico del tercero, quizá pudiera tenerse en cuenta este argumento).

(2) En segundo lugar, está la vía apuntada por Silva Sánchez en su artículo al referirse a la teoría de los cursos causales salvadores. Se llama de esta manera a aquella actividad (realizada por el sujeto en peligro o por quien le auxilia) dirigida a la salvaguarda de algún bien jurídico de un sujeto. La doctrina penal discute acerca de qué tipo de responsabilidad se deriva en el caso de que, o bien quien ha iniciado esa actividad, o bien un tercero, la interrumpa. Los supuestos de infracción del deber de tolerancia, al impedir la acción de salvaguarda, pueden verse como casos de interrupción de un curso causal salvador. El argumento de Silva Sánchez es que quien interrumpe un curso causal salvador incrementa el riesgo del sujeto necesitado y, por tanto, se convierte en garante frente al mismo, y, como tal garante, al infringir el deber de tolerancia se le puede imputar la lesión del bien jurídico (si no entiendo mal, no en comisión por omisión, sino de alguna otra manera que no se especifica en el artículo). En palabras suyas: "Me parece difícil negar que quien interrumpe un curso causal salvador ajeno -aquí, el sujeto que no tolera la conducta realizada en estado de necesidad agresivo- produce un incremento del riesgo de producción del resultado lesivo que amenaza al sujeto necesitado: modifica el statu quo en perjuicio de los bienes de éste". 
Ahora bien, creo que este argumento requiere dos comentarios que lo invalidan: el primero es que, si se asume una concepción de la causalidad como la que he esbozado aquí, no veo razón para pensar que sólo puedan interrumpirse cursos causales salvadores por medio de acciones. De manera que los casos de infracción del deber de tolerancia permitirían imputar al tercero la lesión en los bienes jurídicos del sujeto necesitado no sólo si son realizados por acción, como afirma Silva Sánchez, sino también si la interrupción se ha producido por omisión (y hay posición de garante). El segundo es que, aunque se aceptase que al interrumpir un curso causal salvador se está incrementando el riesgo de que se produzca la lesión, esto no supondría una diferencia respecto de los casos de omisión del deber de socorro. En efecto, si pensamos que al impedir la acción de salvaguarda (o, en general, al interrumpir un curso causal salvador) aumenta el riesgo al que está expuesto el sujeto en peligro, es porque entendemos que aumenta la probabilidad de que esta lesión se produzca. Ahora bien, también en los casos de mera omisión del deber de socorro, al no socorrer, aumentamos la probabilidad de lesión de los derechos del sujeto en peligro. Si alguien se está ahogando y puedo salvarle sin poner en peligro algún bien jurídico propio de entidad comparable, y no lo hago, reduzco las posibilidades de salvación del sujeto. Pero en este caso la doctrina no considera que el sujeto que se niega a auxiliar (aumentando el peligro) tenga posición de garante. Una cosa es crear el riesgo -que es lo que genera la posición de garante-, y otra es aumentarlo.

\section{Recapitulación}

Con todas estas consideraciones, podemos avanzar las siguientes propuestas:

a) No hay una única respuesta a la pregunta acerca de la situación jurídica de quien actúa en estado de necesidad y del sujeto afectado por la acción de salvaguarda, sino que deben ponderarse ciertas circunstancias y los bienes jurídicos en juego para determinar cuál es esta posición. 
_ Sobre el deber de tolerar la acción de salvaguarda en los casos de estado de necesidad agresivo

b) En el caso de que los bienes jurídicos (el que "corre peligro" y el que es necesario para superar el estado de necesidad) sean del mismo valor (esto es, cuando en el caso concreto la lesión que se quiere evitar sea de igual entidad que la que se producirá, situación prevista en la definición de estado de necesidad de la que hemos partido), creo que puede decirse que quien actúa en estado de necesidad tiene meramente una libertad o privilegio de afectar al bien jurídico del otro sujeto (y este último tiene libertad para tratar de impedirlo), porque sería arbitrario que el Derecho protegiera uno de los bienes jurídicos por encima del otro (salvo que concurran razones de otro tipo).

c) En el caso de que el bien jurídico lesionado sea de menor valor que el bien jurídico que se trata de salvar, entonces sí parece adecuado aceptar que quien actúa en estado de necesidad tiene un derecho en sentido estricto. E1 Derecho debe prestar mayor protección a los bienes jurídicos más relevantes frente a los de menor relevancia.

d) Ahora bien, el derecho en sentido estricto de quien actúa en estado de necesidad parece quedar cubierto por el perímetro normativo que acompaña a las situaciones de estado de necesidad, sin que sea un deber de tolerar específico para el caso del estado de necesidad: en unos casos, dependiendo de ciertas circunstancias, el deber de tolerancia no es otra cosa que un derivado del deber de socorro. En otros, se podrá apreciar que el sujeto pasivo de la acción de salvaguarda tiene una posición de garante, por lo que su responsabilidad puede ser mayor.

e) Si lo anterior es correcto, en realidad el deber de tolerancia no es un deber autónomo, correlativo de quien actúa en estado de necesidad, sino un derivado de otros deberes más amplios o distintos (el deber de socorro, los deberes derivados de la posible posición de garante,...) y, por tanto, el derecho de quien actúa en estado de necesidad tampoco es un derecho derivado directamente de su situación de estado de necesidad justificante, sino de la situación más amplia (peligro, derechos frente a un garante, etc.) en la que se encuentra. En definitiva: el deber de tolerancia, en mi opinión, es sólo la manifestación de otros deberes que concurren en las situaciones de estado de necesidad, y no un deber autónomo. 